\title{
ANÁLISE DOS ITENS EM ESTOQUE DE UMA ASSISTÊNCIA TÉCNICA NO RIO DE JANEIRO BASEADA NO QUADRO CONCEITUAL DE VARIABILIDADE
}

\author{
Leandro Alves Nascimento \\ Universidade do Grande Rio José Souza Herdy - UNIGRANRIO \\ Endereço Corporativo \\ leandronascimento@unigranrio.br \\ Leonardo Aragão Guimarães \\ Universidade do Grande Rio José Souza Herdy - UNIGRANRIO \\ Endereço Corporativo \\ professorleo@unigranrio.edu.br
}

\section{RESUMO}

O presente estudo de caso tem por objetivo analisar os itens em estoque de uma assistência técnica baseado no quadro conceitual de variabilidade. Nesta pesquisa são abordadas as ferramentas de planejamento e controle de materiais e níveis de estoque. Deste modo, o grande ganho deste projeto foi conseguir segregar os itens de classe A; B e C dos itens com coeficiente de variação igual a zero. Isto possibilitou identificar que cerca de $87 \%$ do estoque eram de peças obsoletas e que $73 \%$ do capital de giro está empregado nos itens classificados com A. Assim, foi possível obter uma visão gerencial e estratégica do valor investido em peças de reposição da assistência dando a condição para operação de mitigar o risco da falta de materiais importantes para a operação.

Palavra-chave: Apoio a decisão multicritério; Quadro conceitual de variabilidade; Planejamento e controle de estoques; Gestão de serviços; Análise estatística da demanda.

\begin{abstract}
This case study aims to analyze the items in stock of a technical assistance in trought conceptual context of variability. The research is approached as materials planning and control tools and stock levels. Thus, the great to gain was able to segregate the class A items; $B$ and $C$ of items with variabilits coefficient equal to zero. This made it possible to find $87 \%$ of the obsolete parts inventory and 73\% of working capital is currently in the A-rated items. Thus, it was possible to obtain a managerial and strategic view of the amount invested in spare parts of the condition for operation of mitigating the risk of lack of material important to an operation.
\end{abstract}

Keywords: Multicriteria decision support; Conceptual framework of variability; Inventory planning and control; Service management; Statistical analysis of demand.

\section{Como Citar:}

NASCIMENTO, Leandro Alves; GUIMARÃES, Leonardo Aragão. Análise dos itens em estoque de uma assistência técnica no rio de janeiro baseada no quadro conceitual de variabilidade. In: SIMPÓSIO DE PESQUISA OPERACIONAL E LOGÍSTICA DA 
MARINHA, 19., 2019, Rio de Janeiro, RJ. Anais [...]. Rio de Janeiro: Centro de Análises de Sistemas Navais, 2019.

\section{Introdução}

As elevadas taxas de juros e a competitividade acirrada, forçam as organizações a repensarem seus modelos de gestão, pois, outrora, as ações eram reativas às mudanças, mas, atualmente as empresas devem buscar estratégias mais proativas as necessidades dos clientes, compreendendo o papel do relacionamento com os fornecedores como parte das atividades do planejamento empresarial, inserido em todo o contexto do negócio (CHING, 2010. POZO 2015).

A gestão de estoques administra os processos de atendimento a demanda sujeitandoos ao processo de aquisição de suprimentos, por conta disso, o custo de manutenção dos níveis de estoque pode representar de 20 a $60 \%$ dos custos totais que são convertidos em receita a medida em que são consumidos, assim, a redução dos níveis de estoques melhora o fluxo de caixa e o retorno sobre investimentos (ARNOLD, 2012).

Sendo assim, a gestão de materiais deve ser traçada nas vertentes do planejamento, do controle e da retroalimentação, pois, no planejamento será determinado onde deseja-se chegar, o controle será a realidade em que a operação se encontra e a retroalimentação será o indicador do desvio para o alvo, de forma que, o objetivo seja tornar o controle coincidente ao planejamento (CHING, 2010).

\subsection{Objetivo}

O objetivo deste estudo de caso é fazer uma análise crítica do estoque de uma assistência técnica de uma rede de serviços multinacional situada no Rio de Janeiro. Deste modo, pretende-se identificar os itens estratégicos para a operação e aqueles que mais impactam o capital empregado em termos de obsolescência.

\section{Revisão bibliográfica \\ 2.1 A evolução da logística}

Pozo (2015) descreve a evolução da ação e pensamento logístico em cinco partes principais, que vai do escoamento da produção agrícola (Fleury, 2000) e toda a transição e desenvolvimento de operações de bens e serviços (Corrêa \& Corrêa, 2017) até o desdobramento da logística empresarial na cadeia de suprimentos (Ballou, 2010). O quadro 1 sistematiza este desenvolvimento: 


\begin{tabular}{|c|c|c|c|c|c|}
\hline Dis cus são & FASE 1 & FASE 2 & FASE 3 & FASE 4 & FASE 5 \\
\hline Foco & $\begin{array}{c}\text { Es coamento da } \\
\text { produção agrícola } \\
\text { (POZO, 2015). }\end{array}$ & $\begin{array}{l}\text { A logís tica como } \\
\text { es tratégia militar } \\
\text { (BALLOU, 1993). }\end{array}$ & $\begin{array}{c}\text { A integração } \\
\text { rígida (dois-a- } \\
\text { dois) } \\
\text { (NOVAES, } \\
\text { 2007). } \\
\end{array}$ & $\begin{array}{c}\text { As integrações } \\
\text { flexíveis } \\
\text { (NOVAES, 2007). }\end{array}$ & $\begin{array}{c}\text { Supply Chain } \\
\text { Managements - } \\
\text { SCM(WANKE, } \\
\mathbf{2 0 1 1})\end{array}$ \\
\hline Objetivo & 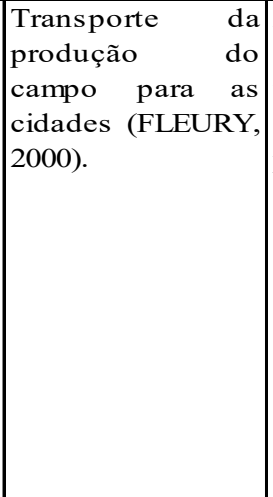 & \begin{tabular}{|lr} 
Abastecimento & de \\
suprimentos & das \\
tropas nos campos & natha. \\
de batalha. & bosterior uso nas \\
empresas privadas e & (POZO, \\
estatais r & (PALOU, \\
2015. & BALLOU \\
$2006)$ &
\end{tabular} & $\begin{array}{|lr|}\text { Racionalização } \\
\text { integrada } & \text { da } \\
\text { cadeia } & \text { de } \\
\text { suprimento. } & \mathrm{O} \\
\text { início } & \text { do } \\
\text { desenvolviment } \\
\text { o de pesquisas } \\
\text { para } & \text { redução } \\
\text { dos } & \text { custos } \\
\text { logísticos } & \text { entre } \\
\text { Os pontos } & \text { de } \\
\text { consumo } & \\
\text { (POZO, } & 2015 . \\
\text { BALLOU, 2006). }\end{array}$ & \begin{tabular}{|lrl}
\multicolumn{2}{|l}{ 年 envolvimento } \\
de estratégias & que \\
otimizaram & os \\
transportes & e & os \\
estoques de & uma \\
época de & crise \\
para diminuir & os \\
custos & totais \\
logísticos & das \\
empresas & \\
(NOVAES, 2007).
\end{tabular} & $\begin{array}{lr}\text { A logística } & \text { como } \\
\text { estratégia } & \text { de } \\
\text { negócio } & \text { (Ballou, } \\
\text { 2006). A tecnologia } \\
\text { da informação na } \\
\text { logística. O mercado } \\
\text { de parcerias entre } \\
\text { elos da cadeia de } \\
\text { suprimentos r } \\
\text { (CHOPRA } \\
\text { MEINDL, 2011). }\end{array}$ \\
\hline Área afetada & $\begin{array}{l}\text { Otimização } \\
\text { modais }\end{array}$ & $\begin{array}{llr}\text { Utilização } & \text { dos } \\
\text { estoques } & \text { com } \\
\text { pulmão entre o } \\
\text { fornecimento e a } \\
\text { demanda (WANKE, } \\
\text { 2011). }\end{array}$ & \begin{tabular}{|l|} 
Sistema de \\
Distribuição \\
(GONÇALVES, \\
2013).
\end{tabular} & 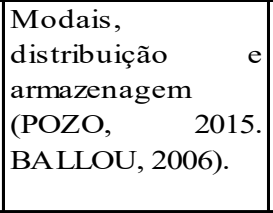 & $\begin{array}{l}\text { Toda a cadeia de } \\
\text { abastecimento } \\
\text { (BALLOU, 2006). }\end{array}$ \\
\hline Época & $\begin{array}{l}-1940 \text { (FLEURY, } \\
2000 \text { ). }\end{array}$ & $\begin{array}{c}\text { De } 1940 \text { a } 1960 \\
\text { (NOVAES, 2004). }\end{array}$ & \begin{tabular}{|} 
De 1960 a 1970 \\
(POZO, 2015).
\end{tabular} & $\begin{array}{c}\text { De 1970 a 1980 } \\
\text { (NOVAES, 2007). }\end{array}$ & $\begin{array}{c}+1980(\text { POZO, } \\
2015)\end{array}$ \\
\hline
\end{tabular}

Quadro 1 - A evolução da logística em cinco fases Fonte: Autores (2019).

Assim, a logística migra para o nível estratégico e passa a integrar toda cadeia de suprimentos, tornando o controle dos fluxos de materiais, dinheiro e informações ainda mais eficazes, contudo, seu objetivo principal torna-se a redução dos custos e a agregação de valor para o consumidor final quebrando diversas fronteiras entre todos os elos da cadeia de suprimentos.

Segundo Mentzer et al. (2001) apud BALLOU (2010):

"O gerenciamento da cadeia de suprimentos é definido como a coordenação estratégica e sistemática das tradicionais funções de negócios e das táticas ao longo dessas funções de negócios no âmbito de uma determinada empresa e ao longo dos negócios no âmbito da cadeia de suprimentos, com o objetivo de aperfeiçoar o desempenho a longo prazo das empresas isoladamente e da cadeia de suprimentos como um todo".

É importante entender que o gerenciamento do SCM resulta em vantagens competitivas e lucratividade a todas as companhias na cadeia de suprimentos além de todos os elementos que integram essa mesma cadeia, sendo que, a balança do sucesso dessa cadeia será a lucratividade de todos os integrantes e não apenas de um estágio individual (CHOPRA \& MEINDL, 2011. BALLOU, 2010).

Segundo Novaes (2007), essas condições são favoráveis a um novo ambiente, um novo modelo de gestão capaz de: (i) Formar parcerias entre fornecedores e clientes ao longo da cadeia; (ii) tornar acessível, entre os parceiros, o acesso mútuo de informações operacionais; (iii) estabelecer uma política ganha-ganha; (iv) aplicar esforços sistemáticos afim de agregar o máximo de valor ao consumidor final e eliminar os desperdícios, minimizando os custos e maximizando a eficiência. 


\subsection{Planejamento e controle de estoques}

Corrêa \& Corrêa (2017), propõe que planejar é "entender como as considerações conjuntas da situação presente e da visão de futuro influenciam as decisões tomadas no presente para que se atinjam determinados objetivos no futuro", embora também possa-se considerar que planejar é estabelecer um plano com dimensões diferentes do passado, mas com variáveis em que se tenha controle total ou parcial no momento. Para isto é preciso ter condições favoráveis ao ambiente de planejamento, portanto, as variáveis devem ser controladas visando à assertividade no momento presente, entretanto, ao menos que se tenha traçado os objetivos a serem alcançados, o planejamento de nada valerá no apoio ao processo decisório (SLACK et al., 2015).

No horizonte de planejamento, as questões sobre o que pedir, quanto pedir e quando pedir, são respondidas à medida que se moldam as "regras do jogo", isto é, as políticas de estoque. Ao alocar as decisões no tempo certo é possível definir como controlar o fluxo de peças, gerir as dispersões dos recursos e administrar seu ressuprimento em função de previsões adequadas (Pozo, 2015). Contudo, ao estabelecer de fato o plano, deve-se, primeiramente, analisar qual o ponto de partida para atingir o objetivo do estoque, seja o nível de serviço, seja minimização de custos, o importante é definir qual a hierarquia das decisões a serem tomadas e qual o impacto, e em quanto tempo, essas decisões trarão resultados a operação (VOLLMANN et al., 2008).

\subsection{Controles agregados}

De forma geral, em qualquer estoque que possua múltiplas Skus armazenadas alguns itens serão mais importantes do que os outros de modo que, controlar tamanha complexidade de forma agregada, possibilitaria uma visão mais vantajosa de todo o estoque, pois, nem todos os produtos, em função de custos ou até mesmo de riscos, tem o mesmo impacto e por isto não demanda a mesma atenção gerencial (SLACK et al., 2015).

Em um controle mais agregado inserir os produtos em dado número de categorias e aplicar sob essas categorias uma política de controle diferenciada e diligente, tendo em vista que, nem todos os produtos possuem a mesma margem de lucro, demanda ou competitividade. Logo, as regras do jogo, quando bem administradas para cada um desses ambientes, possibilita a operação atingir os níveis de serviço com níveis de estoques menores, diferente de uma política única, que propõe as mesmas condições para todos os itens, tendendo a níveis maiores de estoques para todos os produtos (BALLOU, 2010).

\subsection{Classificação ABC}

A classificação ABC é uma ferramenta que identifica os itens de maior importância no estoque. A técnica torna possível focar nos itens “poucos vitais” e ganhar mais tempo sob os "muitos triviais" a partir de um controle agregado com políticas diferentes para cada classe de itens (CORRÊA \& CORRÊA, 2017. VOLLMANN et al., 2008), Para Slack et. al., (2015) as classes $\mathrm{A}$, B e $\mathrm{C}$ podem ser definidas conforme a figura 1 : 


\begin{tabular}{|c|c|}
\hline Classe & Definição da classe \\
\hline $\mathbf{A}$ & $\begin{array}{l}\text { Faixa que contém geralmente contém } 20 \% \text { dos produtos de alto valor que } \\
\text { representam cerca de } 80 \% \text { do custo total em estoque. }\end{array}$ \\
\hline B & $\begin{array}{l}\text { Nesta categoria são tratadas SKUS de valor médio, conceitualmente os } \\
30 \% \text { de produtos seguintes que representam em torno de } 15 \% \text { do custo } \\
\text { total. }\end{array}$ \\
\hline $\mathrm{C}$ & $\begin{array}{l}\text { Já neste grupo observa-se as peças de baixo valor que, embora seja a } \\
\text { maior parte do estoque, em questão de volume, provavelmente } \\
\text { representamapenas } 5 \% \text { do valor total do estoque. }\end{array}$ \\
\hline
\end{tabular}

Figura 1 - Classificação ABC

Fonte: Adaptado de SLACK et al. (2015).

A curva ABC pode se comportar de diversas maneiras em função da série de dados analisada. Quando todo o estoque tem o mesmo custo, a dispersão de dados limita-se a uma reta inclinada crescente, indicando ausência de concentração de importância neste critério. Entretanto, quando a distribuição do custo é seletivamente sustentada, percebe-se uma forte concentração de recursos alocado aos itens mais importantes, de acordo com a intensidade da curva.

Em um sistema de estoques perpétuo as melhorias nos processos de previsões de demanda e nas decisões de quanto pedir e quando pedir possibilitam maior ganho quando à concentração dos esforços são direcionados para A, por conta do alto custo envolvido. Os mesmos esforços adotados em C não trazem resultados tão significativos, por estes representarem a menor parcela do custo (VOLLMANN et al. 2008)

Contudo, quando a classificação do estoque é feita apenas com um critério a tendência é ignorar outros fatores que contribuem para decisões mais efetivas na operação. A análise do sistema com critérios múltiplos pode levar a identificação do que manter disponível e o que oferecer por políticas de encomendas, assim, diminuindo os níveis de estoque imobilizado (BALLOU, 2010).

\subsection{Classificação mútua - ABC x Criticidade}

Além dos custos, outro critério importante a ser notado é a criticidade que leva à tona aspectos como o impacto que a falta do item pode trazer a operação, a rapidez e a pontualidade na reposição e na possibilidade de substituição no caso da falta (VOLLMANN et al., 2008).

Um ponto que deve ser levantado na criticidade é a movimentação dos materiais, considerando a falta de um item de alto giro como perda direta de venda, pois, a ausência desses recursos impacta diretamente na competitividade da empresa diminuindo potencial de serviço oferecido ao cliente. A criticidade, abordando como critério principal a movimentação, pode ser descrita como:

I - Poucos Itens que correspondem, em geral, $80 \%$ do volume da demanda.

II - Itens intermediários, podem ocupar até $15 \%$ do volume de saídas.

III - Muitos itens de baixa ou nenhuma demanda no período.

\begin{tabular}{cccc}
\hline $\begin{array}{c}\text { Classificação } \\
\text { final }\end{array}$ & \multicolumn{3}{c}{ Classes agrupadas } \\
\hline AA & AI & AII & BI \\
BB & AIII & BII & CI \\
CC & BIII & CII & CIII \\
\hline
\end{tabular}

Tabela 1 - Classificação ABC com múltiplos critérios

Fonte: Adaptado de VOLLMANN et al. (2008). 
Em alguns casos a criticidade pode ser mais pesada que o custo de manutenção da peça, por conta disso, ambos critérios devem ser analisados em conjunto conforme a tabela a 1 (CORRÊA \& CORRÊA, 2017).

\subsection{Classificação multicritério}

Logo ideal é que seja mantido um pequeno número de classificações para otimizar o gerenciamento. Por conta disso, serão estimadas as seguintes classes para combinação dos critérios, levando em consideração os pontos mais fortes de cada ponderação no quadro 2 a seguir (VOLLMANN, 2008):

\begin{tabular}{cccc}
\hline Categorias & \multicolumn{3}{c}{ Criticidade } \\
\hline Custos & I & II & III \\
\hline A & AI & AII & AIII \\
B & BI & BII & BIII \\
C & CI & CII & CIII \\
\hline \multicolumn{4}{c}{ Quadro 2 } \\
Fonte: Classificação multicritério \\
\end{tabular}

Feito isto, deve-se definir políticas específicas para cada categoria de modo que sejam avaliados pontos críticos como controles por inventários, lotes de pedidos, estoques de segurança, métodos de previsão de demanda, modelos de reposição e, até mesmos, reclassificações dos itens, pois, essas decisões impactam significativamente no ganho da operação (SLACK et al., 2015. POZO, 2015).

\begin{tabular}{|c|c|c|c|}
\hline \multirow[b]{2}{*}{ Políticas } & \multicolumn{3}{|c|}{ Categoria } \\
\hline & $\mathbf{A A}$ & BB & $\mathbf{C C}$ \\
\hline Inventários & Mensal & A cada seis meses & Anual \\
\hline Lote de pedido & $\begin{array}{l}\text { LEC, mas } \\
\text { depende da } \\
\text { criticidade } \\
\end{array}$ & LEC & $\begin{array}{l}\text { Grandes } \\
\text { quantidades }\end{array}$ \\
\hline $\begin{array}{l}\text { Estoque de } \\
\text { segurança }\end{array}$ & $\begin{array}{l}\text { Grandes para } \\
\text { itens críticos }\end{array}$ & $\begin{array}{l}\text { Grande para itens } \\
\text { críticos }\end{array}$ & $\begin{array}{l}\text { Alto ou nulo, } \\
\text { depende da } \\
\text { criticidade }\end{array}$ \\
\hline Modelo de reposição & $\begin{array}{l}\text { Ponto de } \\
\text { pedido }\end{array}$ & Ponto de pedido & $\begin{array}{l}\text { Período fixo, lote } \\
\text { variável ou sob } \\
\text { encomendas } \\
\text { (depende da } \\
\text { criticidade) }\end{array}$ \\
\hline Previs ão de demanda & Item-a-item & Item-a-item & $\begin{array}{l}\text { Previsões mais } \\
\text { agregadas }\end{array}$ \\
\hline Reclass ificação & Por semestre & Por semestre & Anual \\
\hline Nível de s erviço & Alto & $\begin{array}{l}\text { Alto ou baixo, } \\
\text { conforme a } \\
\text { demanda. }\end{array}$ & baixo \\
\hline Controle & Rígido & Rígido & Simples \\
\hline
\end{tabular}

\subsection{O efeito da variabilidade sobre a demanda e o controle dos estoques}

Para Vollmann et al. (2008) a partir da análise do coeficiente de variabilidade podese definir os pontos que retratam o comportamento dos itens em relação a demanda histórica podendo separá-los em classes por faixas do coeficiente de variação. Conforme observado em Wanke (2012) e Tavares \& Almeida (1983) destacam-se os seguintes pontos no quadro conceitual: 


\begin{tabular}{|c|c|c|c|c|}
\hline Classe & Quanto a demanda & $\begin{array}{c}\begin{array}{c}\text { Quanto a previsão de } \\
\text { demanda }\end{array} \\
\end{array}$ & $\begin{array}{c}\text { Quanto a participação em } \\
\text { quantidade de itens }\end{array}$ & $\begin{array}{c}\text { Quanto a participação em } \\
\text { custos totais }\end{array}$ \\
\hline 0,01 a 0,20 & Demandas mais estáveis & Mais precisas & \multirow[b]{2}{*}{ Baixa } & Baixo \\
\hline 0,21 e 0,40 & $\begin{array}{c}\text { Demanda constante, mas, com } \\
\text { maiores oscilações que a } \\
\text { classe até } 0,20\end{array}$ & $\begin{array}{c}\text { Precisão regular com maior } \\
\text { probabilidade de erro que a } \\
\text { classe até } 0,20\end{array}$ & & \multirow[b]{2}{*}{ Alto/médio/baixo } \\
\hline $\begin{array}{l}0,61 \text { a } 0,80 \\
0,81 \text { a } 1,00\end{array}$ & \multirow[t]{3}{*}{ Demanda instável } & \multirow[t]{3}{*}{$\begin{array}{l}\text { Baixa precisão, a melhor } \\
\text { forma de é por meio de } \\
\text { previsões agregadas por } \\
\text { compensação. }\end{array}$} & \multirow[t]{2}{*}{ Média } & \\
\hline $\begin{array}{l}1,01 \text { a } 1,20 \\
1,21 \text { a } 1,40\end{array}$ & & & & \multirow{3}{*}{ Alto } \\
\hline Maior que 1,4 & & & \multirow[b]{2}{*}{ Alta } & \\
\hline 0 (zero) & $\begin{array}{c}\text { Não há registro suficiente } \\
\text { para análise }\end{array}$ & $\begin{array}{l}\text { Itens novos ou não } \\
\text { possuíram demanda no } \\
\text { horizonte analisado. }\end{array}$ & & \\
\hline
\end{tabular}

A partir da viabilização dessas análises é possível conhecer a presente complexidade do estoque e traçar um plano de gestão que permita alcançar resultados mais satisfatórios com o uso de políticas mais adequadas aos diversos itens em estoque. Desta forma, propõe-se que o grupo classificado com o coeficiente igual a zero seja separado dos demais, de modo que, sejam analisados cuidadosamente pois a presença desses itens impacta em elevados custos fixos alocados em itens que não possuem demanda suficiente para cobri-los (WANKE, 2012. TAVARES \& ALMEIDA, 1983. SLACK, 2015).

\section{Metodologia}

Esta pesquisa pode ser classificada como descritiva, por apresentar as características do negócio da empresa XYZ com a variável planejamento de estoques, analisando o seu modelo de gestão e controle de materiais. Não obstante, este estudo também é classificado como explicativo por utilizar os dados gerados pela empresa na movimentação dos materiais para explicar o comportamento da demanda dos clientes. Neste caso o universo de aplicação da pesquisa seria a própria organização enquanto a amostra é o setor que será analisado.

A tratativa dos dados foi desenvolvida por meio qualitativo e quantitativo, este quando se trata do uso de metodologias volta ao controle de materiais e aquele quando se utiliza de informações obtidas de entrevistas informais com os membros da operação.

A metodologia de trabalho utilizado para a análise do problema é apresentada na figura 2 e teve como ponto de partida a análise da demanda dos últimos anos para a verificar o grau da variabilidade das Skus em estoque, assim como, identificar os poucos vitais e os menores triviais:

\begin{tabular}{|l|l|}
\hline 1 & - Análise da demanda dos últimos anos \\
\hline 3 & - Realização do inventário \\
\hline 5 & - Somparação do quadro conceitual com o controle de estoques atual \\
\hline
\end{tabular}

Figura 2 - Metodologia utilizada para análise do problema Fonte: Autores (2019). 
No último passo da figura 2 foi apresentado o quadro comparativo entre o que deveria ter disponível em estoque e o que deveria ser comprado sob encomenda de clientes sendo também apresentada uma extrapolação do custo do estoque em função do nível de serviço de $95 \%$.

\section{Estudo de caso}

A Empresa XYZ refrigeração LTDA-ME é uma microempresa que atua na área de serviços e atualmente faz parte da rede de serviços Autorizados de uma grande multinacional sueca, que será nomeada como WG, sendo também contratada por uma grande seguradora brasileira com o mesmo propósito do grupo WG: atender os clientes pós-venda do seguimento de linha branca.

Atualmente a empresa comporta 17 funcionários sendo eles três de nível tático enquanto os demais estão no nível operacional. A empresa é de cunho familiar e não utiliza linguagem técnica para alocação de atividades, logo, níveis como gerentes e supervisores estão no mesmo patamar enquanto operação e administrativos também são equivalentes.

A empresa não possui indicadores que monitorem o comportamento do estoque, comprando em excesso peças que historicamente não possuem um grau interessante de giro. A falta de controle aumenta os custos da operação, impedindo que o capital investido seja transformado em receita até que seja efetivada uma venda ou seja literalmente perdido em caso de obsolescência.

Além de acumular peças imobilizadas no estoque, o ressuprimento dos itens que possuem maior número de saídas não corresponde a demanda dos clientes, devido à ausência de um estoque de segurança que amorteça a demanda enquanto há novos lotes de pedidos em trânsito, o que diminui o nível de serviço oferecido, aumentando os custos por falta de estoque - perdas de vendas, trocas de produtos acabados por falta de peça, processos judiciais por falta de atendimento etc.- gerando insatisfação dos consumidores que não tem a peça certa no local e tempo certo, conforme o gráfico 1.

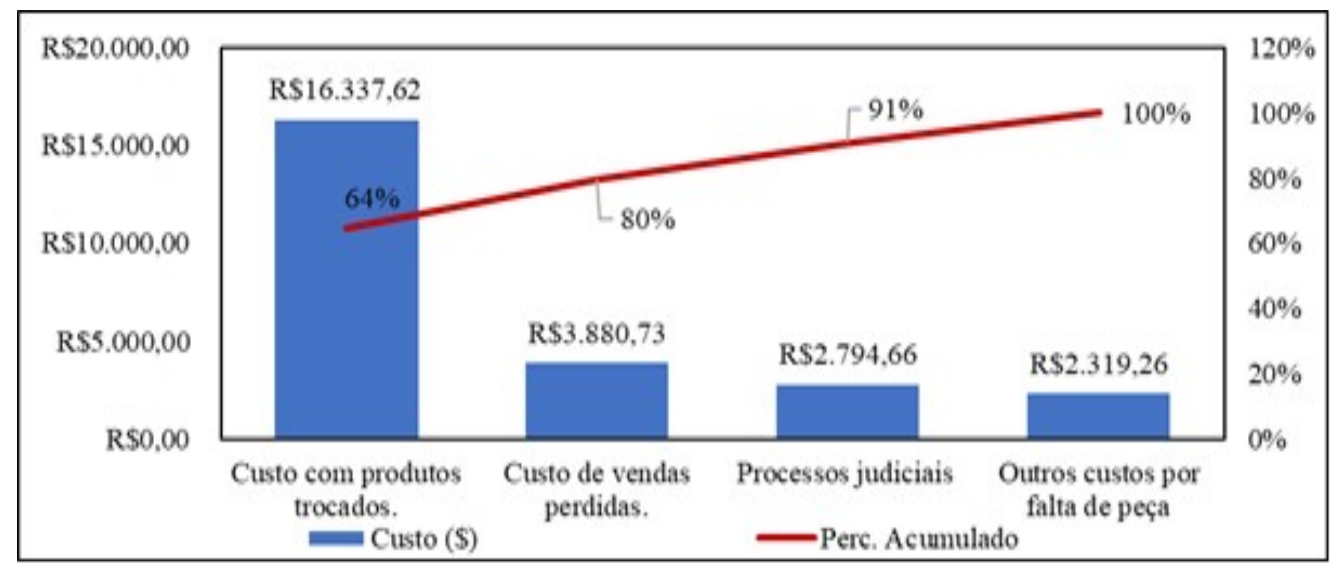

Gráfico 1 - Alocação dos custos causados pelo baixo nível de serviço em 2016.

Fonte: Autores (2019).

O gráfico 1 demostra o prejuízo gerado pela falta de peças que poderiam ser classificadas com médio e/ou alto giro no estoque, observa-se que o custo com a perda de vendas representa aproximadamente $15 \%$ do total do prejuízo acumulado durante o ano e o campo mais afetado é o custo com troca de produtos, que representa mais de $64 \%$ do custo total, ambos campos citados espelham o nível de serviço refletindo a insatisfação ao consumidor. 


\begin{tabular}{|c|c|c|c|c|c|c|c|}
\hline \multirow{3}{*}{$\begin{array}{c}\text { Classe } \mathbf{C V} \\
0\end{array}$} & \multicolumn{2}{|r|}{2015} & \multicolumn{3}{|c|}{2016} & \multicolumn{2}{|r|}{2017} \\
\hline & \multirow{2}{*}{$\begin{array}{l}\text { Qtd } \\
173\end{array}$} & Custo & \multirow{2}{*}{$\begin{array}{l}\text { Qtd } \\
817\end{array}$} & \multicolumn{2}{|c|}{ Custo } & \multirow{2}{*}{$\begin{array}{l}\text { Qtd } \\
839\end{array}$} & Custo \\
\hline & & RS $15.269,17$ & & RS & $96.941,40$ & & RS $98.881,88$ \\
\hline 0,01 a 0,20 & & & & & & 4 & RS $\quad 192,50$ \\
\hline 0,21 a 0,40 & 104 & $9.153,59$ & 521 & RS & $41.132,08$ & 569 & RS $40.663,65$ \\
\hline 0,41 a 0,60 & 423 & RS $61.134,94$ & 3072 & RS & $336.743,79$ & 2218 & RS $247.850,48$ \\
\hline 0,61 a 0,80 & 369 & RS $48.463,82$ & 2974 & RS & $358.095,31$ & 2920 & RS $364.438,81$ \\
\hline 0,81 a 1,00 & 107 & RS $15.704,72$ & 1056 & RS & $162.318,78$ & 1004 & RS $129.199,86$ \\
\hline 1,01 a 1,20 & 6 & RS $\quad 473,41$ & 42 & RS & $5.480,84$ & 122 & RS $\quad 8.889,86$ \\
\hline 1,21 a 1,40 & 17 & $2.822,94$ & 32 & RS & $2.942,65$ & 126 & RS $18.631,26$ \\
\hline$>1,40$ & 4 & $3.694,30$ & 2 & RS & 284,18 & 2 & RS $\quad 568,35$ \\
\hline Total Geral & 1203 & RS $156.716,89$ & 8516 & RS & $.003 .939,03$ & 7804 & RS 909.316,65 \\
\hline
\end{tabular}

\begin{tabular}{c|cc|cc|cc}
\hline \multicolumn{7}{c}{ Represent ação (\%) de quantidades e custos por periodo } \\
0 & $14,38 \%$ & $9,74 \%$ & $9,59 \%$ & $9,66 \%$ & $10,75 \%$ & $10,87 \%$ \\
\hline 0,01 a 0,20 & $0,00 \%$ & $0,00 \%$ & $0,00 \%$ & $0,00 \%$ & $0,05 \%$ & $0,02 \%$ \\
\hline 0,21 a 0,40 & $8,65 \%$ & $5,84 \%$ & $6,12 \%$ & $4,10 \%$ & $7,29 \%$ & $4,47 \%$ \\
\hline 0,41 a 0,60 & $35,16 \%$ & $39,01 \%$ & $36,07 \%$ & $33,54 \%$ & $28,42 \%$ & $27,26 \%$ \\
0,61 a 0,80 & $30,67 \%$ & $30,92 \%$ & $34,92 \%$ & $35,67 \%$ & $37,42 \%$ & $40,08 \%$ \\
\hline 0,81 a 1,00 & $8,89 \%$ & $10,02 \%$ & $12,40 \%$ & $16,17 \%$ & $12,87 \%$ & $14,21 \%$ \\
\hline 1,01 a 1,20 & $0,50 \%$ & $0,30 \%$ & $0,49 \%$ & $0,55 \%$ & $1,56 \%$ & $0,98 \%$ \\
\hline 1,21 a 1,40 & $1,41 \%$ & $1,80 \%$ & $0,38 \%$ & $0,29 \%$ & $1,61 \%$ & $2,05 \%$ \\
\hline$>1,40$ & $0,33 \%$ & $2,36 \%$ & $0,02 \%$ & $0,03 \%$ & $0,03 \%$ & $0,06 \%$ \\
Total Geral & $\mathbf{1 0 0 , 0 0 \%}$ & $\mathbf{1 0 0 , 0 0} \%$ & $\mathbf{1 0 0 , 0 0} \%$ & $\mathbf{1 0 0 , 0 0} \%$ & $\mathbf{1 0 0 , 0 0 \%}$ & $\mathbf{1 0 0 , 0 0} \%$ \\
\hline
\end{tabular}

Tabela 3 - Cenário 1: Análise de três anos da demanda Fonte: Autores (2019).

A classe CV igual a zero representa uma característica singular da operação de serviços, uma vez que, nesta classe estão inseridos itens com demanda única ou esporádica com grande espaçamento de tempo o que implica em atender a demanda circunstancialmente contra pedido, podendo ser a melhor decisão no curto prazo (Rego \& Mesquita, 2011). Este grupo representa os 66,26\% dos itens que já passaram pelo estoque, entretanto, essas ocasiões são circunstanciais tanto que representaram pouco mais que $10 \%$ do custo total do estoque.

Os itens dentro do intervalo entre 0,41 e 0,60 representam cerca de um terço do custo total com uma tendência a queda (\%) tanto em volume de vendas quanto em participação em custos totais com uma instabilidade moderada:

- Em $2015 \rightarrow$ 35\% de itens representavam 39\% do custo.

- Em $2016 \rightarrow$ 36\% de itens representavam 33\% do custo.

- $\quad$ Em $2017 \rightarrow$ 28\% de itens representavam 27\% do custo.

Já as Skus com o coeficiente de variação entre 0,61 e 0,80 - que já chegam a representar cerca de $37 \%$ do custo total - apresentam um certo crescimento (\%) tanto em quantidade de itens quanto em custo associado, porém, com a variabilidade superior as peças com o CV até 0,60 :

- $\quad$ Em $2015 \rightarrow$ 31\% de itens representavam 31\% do custo.

- Em $2016 \rightarrow$ 35\% de itens representavam 36\% do custo.

- $\quad$ Em $2017 \rightarrow$ 37\% de itens representavam 40\% do custo.

Somando-se as duas faixas com coeficiente de variação entre 0,41 e 0,80 nota-se que aproximadamente $68 \%$ dos itens que já passaram pelo estoque representaram também $68 \%$ do custo investido. E que apesar dos itens que possuem o CV igual a zero serem superiores em quantidade de itens individuais a sua relação de custo é bem inferior as classes onde, apesar de instável, possuem uma demanda mais representativa além do volume maior em quantidade vendida. 


\section{Resultados}

Uma vez que já se tenha em mãos o que de fato tem giro na operação e qual o grau de variabilidade da demanda desses itens o próximo passo é comparar os níveis de estoque das Skus com as informações levantadas como mostra o gráfico 3:

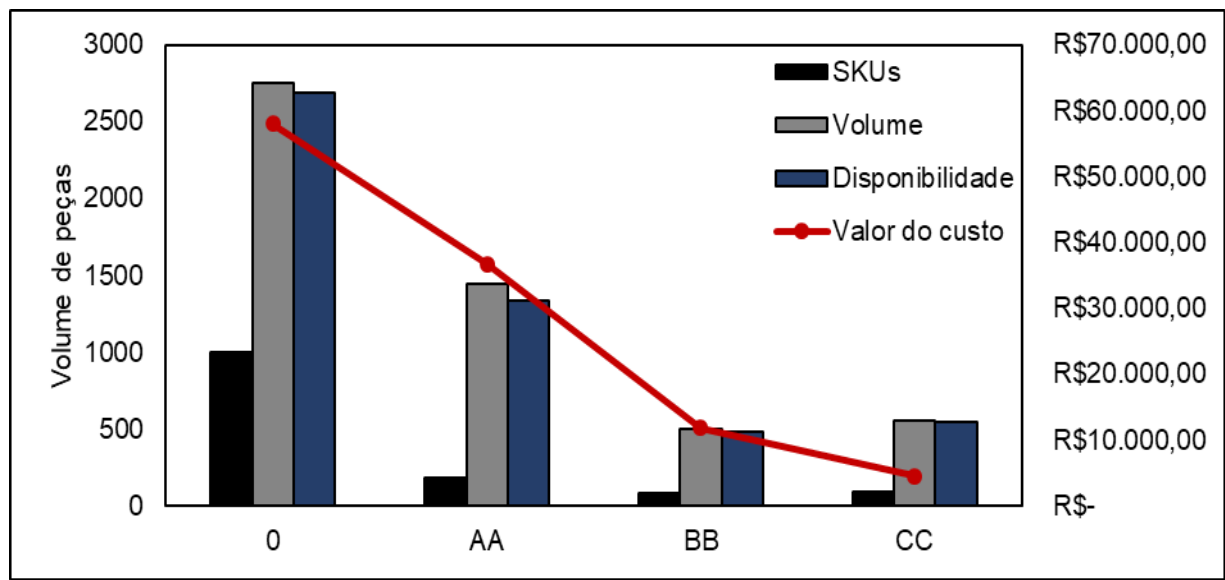

Gráfico 3 - Análise de estoque baseado em SKU, Disponibilidade e custos. Fonte: Autores (2019).

A partir do gráfico 3 pode-se observar que:

- 53\% da composição do estoque é formada por Skus com coeficiente de variação igual a zero, isto é, possuem demanda média menor que uma unidade por ano, estas peças representam aproximadamente $\mathrm{R} \$ 58.000,00$, isto é, mais da metade do valor em estoque.

- Uma discrepância notada foi o nível de disponibilidade dessa classe ser próximo a quantidade em estoque, logo, o que deveria estar reservado para OSs dedicadas está disponível para outros serviços e, conceitualmente, não deveria.

- De acordo com a tabela 3, 87,45\% dos itens que deram entrada no estoque em dois anos com baixíssimo consumo continuam no estoque formando capital imobilizado.

- Apenas 183 Skus são possuem giro no estoque e representam 33\% do valor total em estoque.

- Com base na aplicação do controle de estoques multicritérios percebeu-se que em estoque estavam aproximadamente apenas $74 \%$ Skus de giro.

- As classes BB e CC possuem cerca de 50\% dos códigos analisados.

- Ao total o inventário de peças de reposição da empresa tem 1362 Skus totalizando 5247 peças com um custo médio em estoque de aproximadamente R\$110.000,00.

Com esta análise fica claro que realmente faltam peças importantes no estoque e que o baixo nível de serviço oferecido (73,79\%) impacta diretamente nos atendimentos técnicos ocasionando o desperdício de espera, pois, o cliente, caso queira aguardar, só terá seu produto reparado em torno de 25 dias. Conforme é sintetizado pela tabela 4: 


\begin{tabular}{|c|c|c|c|c|c|}
\hline Multicritério & Skus & Análise histórica & (\%) Comparativo & Volume de peças & Custo \\
\hline AA & 183 & 248 & $73,79 \%$ & 1440 & R $\$ 36.737,61$ \\
\hline BB & 83 & 166 & $50,00 \%$ & 500 & R $\$ 11.761,03$ \\
\hline CC & 93 & 170 & $54,71 \%$ & 555 & R $\$ 4.454,60$ \\
\hline 0 & 1003 & 1147 & $87,45 \%$ & 2752 & R\$ $57.960,79$ \\
\hline
\end{tabular}

Tabela 4 - Análise do estoque na situação atual Fonte: Autores (2019).

Embora o Autores tenha sido procurado pelo gestor da empresa apenas para analisar os dados históricos e identificar quais seriam os materiais estratégicos para a empresa em termos de disponibilização do capital de giro empregado para manter a operação de serviços ativa. Foram prescritas algumas ações para a prestadora de serviços para mitigar este impacto no médio/longo prazo.

Sejam elas:

- Não fazer mais aquisição dos itens classificados como "ZERO”;

- Aumentar o controle sobre os itens classificados como “A” para aumentar o giro dos materiais e reduzir o custo do capital empregado para ativos circulantes;

- Aderir as políticas de estoque Ponto de Pedido (classe A) e Estoque Máximo U (Classes B e C).

\section{Conclusão}

O presente estudo de caso teve como objetivo analisar os itens de uma assistência técnica no Rio de Janeiro através da curva ABC e da Criticidade. No entanto, nesta análise também foi introduzido o conceito de análise da variabilidade da demanda através do coeficiente de variação.

Deste modo, foi possível alcançar resultados mais precisos e estratégicos, pois, foram identificados cerca de 2752 itens que estavam armazenados, porém, sem qualquer índice de giro nos últimos quatro anos de análise.

Embora tenham sido feitas prescrições quanto aos materiais, com o objetivo de mitigar os custos envolvidos e toda a operação envolvida, não foi obtido os resultados quanto o uso das ações, pois, a empresa não permitiu o acesso a essas informações.

Por fim, pode-se comprovar a efetividade do quadro conceitual da variabilidade e de sua interação com a classificação ABC. Logo, ficou claro que a utilização de uma classificação multicritério é mais efetiva do que analisando apenas por um lado do prisma operacional.

\section{Referências bibliográficas}

[1] ARNOLD, J. R. Tony. Administração de Materiais. São Paulo. Atlas 2012.

[2] BALLOU, Ronald H. Gerenciamento da Cadeia de Suprimentos: planejamento, organização e logística empresarial. Porto Alegre: Bookman, 2010.

[3] — Henrique L. CORRÊA, Carlos A. Administração da produção e operações manufatura e serviços: uma abordagem estratégica. São Paulo. Atlas. 2017.

[4] CHING, Hong Yuh. Gestão de estoques na cadeia logística integrada: Supply Chain. $4^{\mathrm{a}}$ ed. São Paulo. Atlas. 2010.

[5] CHOPRA, Sunil. MEINDL, Peter. Gestão da cadeia de suprimentos: Estratégia, 
Planejamento e Operações. São Paulo. $4^{\mathrm{a}}$ Ed. Pearson. 2011.

[6] MENTZER, John T. WITT, William De. KEEBLER, James S. MIN, Soonhong, NIX, Nancy W. SMITH, Carlo D. ZACHARIA, Zach G. “Defining Supply Chain Management”, Journal of Business Logistics, Vol. 22, $n^{\circ}$ 2, 2001.

[7] NOVAES, Antônio G. Logística e Gerenciamento da Cadeia de Distribuição. $3^{\text {a }}$.ed. Rio de Janeiro, 2007.

[8] POZO, Hamilton. LOGÍSTICA E GERENCIAMENTO da CADEIA DE SUPRIMENTOS: Um Enfoque para os Cursos Superiores de Tecnologia. São Paulo: Atlas, 2015.

[9] SLACK, Nigel. BRANDON-JONES, Alistair. JOHNSTON, Robert. Administração da Produção. 4 Ed. São Paulo: Editora Atlas. 2015.

[10] TAVARES, L. V.; ALMEIDA, L. T. A binary decision model for stock control os very low moving items. Operational Research Society, v. 34, n. 3, p. 249-252, 1983.

[11] VOLLMANN, Thomas E.; BERRY, Willian L., WHYBARK, D. Clay; JACOBS, F. Robert. Sistemas de Planejamento \& Controle da Produção para o Gerenciamento da Cadeia de Suprimentos. 5 ed. São Paulo: Bookman, 2008.

[12] WANKE, Peter. Gestão de Estoques na Cadeia de Suprimentos: Decisões e modelos

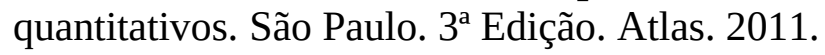

[13] — Peter. Quadro conceitual para gestão de estoques: enfoque nos itens. Gestão \& Produção - Universidade Federal de São Carlos. vol.19 no.4 São Carlos out./dez. 2012.

[14] YIN, R. K. Estudo de caso: planejamento e métodos. 5.ed. Porto Alegre: Bookman, 2015. 